\title{
Comparative Study of Oral versus Intravenous Iron Therapy in Patients of Chronic Renal Failure Receiving Recombinant Human Erythropoietin
}

\author{
Sadat Memon, Nasreen Qazi, Shafiq ur Rehman Memon, Jamil Laghari
}

\begin{abstract}
OBJECTIVE: To evaluate the effects of oral and intravenous Iron on serum ferritin and total Iron binding capacity in patients of chronic renal failure receiving recombinant human erythropoietin.

METHODOLOGY: This prospective comparative interventional study was conducted in the Department of Pharmacology and Therapeutics LUMHS Jamshoro with the collaboration of Urology Department of Liaquat University Hospital (LUH) Jamshoro and Hyderabad, for the duration of 6 months after approval from research ethics committee of the institute. By using Rao software sampling calculator and after following inclusion and exclusion criteria 80 patients were taken and divided into two groups, Group A (Oral Iron+rHuEPO) \& Group B (I/V Iron+rHuEPO). Informed consent was taken from all patients. Serum ferritin \& TIBC were done at the beginning and at the end of the six months. Data was analyzed on SPSS version 16.0 (IBM, Incorporation, USA). The continuous variables were analyzed by student's t-test. The significant $p$-value was taken at $\leq 0.05$.

RESULTS: Significant statistical improvement was observed in Serum Ferritin and TIBC of both Groups (Group A and Group B). But there is more prominent improvement in serum ferritin and TIBC of Group B (I/V iron + rHuEPO). No adverse effects of iron therapy and erythropoietin therapy were observed in patients of both groups.
\end{abstract}

CONCLUSION: The present study concludes that treatment with I/V Iron + Erythropoietin therapy significantly improves Serum Ferritin and TIBC of CRF patients of Group B who received Intravenous Iron Dextran $2 \mathrm{ml}$ diluted in $200 \mathrm{ml}$ normal saline twice a month + rHuEPO 2000 IU SC twice a week.

KEY WORDS: Chronic Renal Failure (CRF), Total Iron Binding Capacity (TIBC), Human Recombinant Erythropoietin (rHuEPO).

This article may be cited as: Memon S, Qazi N, Memon SR, Laghari J. Comparative Study of Oral versus Intravenous Iron Therapy in Patients of Chronic Renal Failure Receiving Recombinant Human Erythropoietin. J Liaquat Uni Med Health Sci. 2019;18(01):42-6.

doi: 10.22442/jlumhs.191810599

\section{INTRODUCTION}

Anemia is defined as the level of hemoglobin or Red Blood Cells (RBCs), less than the reference levels, which is because of the rapid loss or because of the very low production. Anemia is one of the most important features of chronic kidney failure, when chronic kidney disease progresses, the functions of the kidney become worse. Filtration capability of the kidneys and the anemia has close relationship, lesser the glomerular filtration rate more severe will be the anemia ${ }^{1}$.

The symptoms of anemia are difficulty in breathing, easy fatigability, poor cognition function with reduced physical activity. Appetite, sexual drive, sleep and immunological response are also decreased. Anemia accelerate the output of the heart, with acceleration of the left ventricle hypertrophy which can lead to heart failure $^{2,3}$.
Recent studies also suggest that anemia can cause chronic renal shut down which is referred as one of the most important and significant feature that have surely amplified the mortality and morbidity among these patients. The reduction in erythropoietin level is the major reprobate for the development of anemia in patients of chronic renal shut down ${ }^{4}$.

Erythropoietin, a glycoprotein hormone is synthesized $(80 \%)$ by the type 1 renal fibroblast cells and inside the liver $(20 \%)$. The mean corpuscular volume of red blood cells is essentially controlled by the erythropoietin ${ }^{5}$.

The severity of iron deficiency anemia is measured by Serum ferritin values of $\mathrm{r} 30 \mathrm{ng} / \mathrm{ml}$, which indicates deficiency of iron, these levels predicts the absent stores of iron in the bone marrow. The availability of iron for production of red blood cells is measured by Total Iron Binding Capacity (TIBC) ${ }^{6}$. 
A significant amount of blood is lost during the dialysis procedure, which tends to remain inside the dialysis machine, which can cause iron deficiency anemia in the chronic renal failure patients. 1.5 to 2.0 gram of iron is supposed to be lost from the body per year, by the dialyzed patients ${ }^{7}$, so if these patients do not receive exogenous iron, they will have low iron levels in their bodies and ultimately their iron stores will also be exhausted ${ }^{8}$.

The recombinant human erythropoietin is synthesized by the recombinant DNA technology which resembles both physiologically and structurally to the natural erythropoietin (EPO) ${ }^{9-11}$.

Recombinant technology of human erythropoietin has played an enormous role for the past many years for the treatment of CRF patients. It has magnificent effects on the quality of lives of the dialyzing patients with improved performance of heart ${ }^{12}$.

Iron therapy is initiated to improve the accessible stores for erythropoiesis, to enhance the iron levels in the body and to prevent anemia complications in the CRF patients ${ }^{13}$. The iron therapy given orally is easily available, inexpensive where no expert is required. But due to its impaired absorption via gastrointestinal tract has constrained its use. The therapy administered through intravenous route avoids all such adverse effect and provides marked bioavailability of the iron ${ }^{14-16}$.

This study was conducted to evaluate the efficacy of two iron preparations, oral and parenteral, for the correction of anemia by estimating serum ferritin and TIBC levels in chronic renal failure patients receiving Recombinant Human Erythropoietin (rHuEPO).

\section{METHODOLOGY}

This prospective comparative interventional study was carried out by the Department of Pharmacology and Therapeutics LUMHS, Jamshoro for Six months with the collaboration of Urology department of LUH Jamshoro and Hyderabad. Sample size was calculated by using Rao-soft sampling calculator. The sample size was $n=80$.

All Patients were divided into 2 groups. Group A: 40 patients were included. They received Tab: ferrous sulphate $200 \mathrm{mg}$ orally 3 times a day + rHuEPO $2000 I U$ SC twice a week. Group B: 40 patients were included who received Intravenous Iron Dextran $2 \mathrm{ml}$ diluted in $200 \mathrm{ml}$ normal saline twice a month + rHuEPO 2000IU SC twice a week.

Inclusion Criteria includes Age 25 years and above, Known cases of chronic renal failure (CRF) who were anemic and on conservative treatment, Patients with 5 $-8 \mathrm{~g} / \mathrm{dl}$ Hemoglobin. Patients with Serum Ferritin $10 \mu \mathrm{g} /$ dl. Patients with TIBC $450 \mu \mathrm{g} / \mathrm{dl}$.

Exclusion Criteria Patients with anemia due to some other cause other than erythropoietin deficiency. On androgen therapy within last one month, with associated coronary artery disease, with chronic infectious diseases like chronic hepatitis, tuberculosis etc, with uncontrolled hypertension, who were not willing to participate in the study.

Blood Sample was taken by means of sterilized disposable syringe from anterior cubital vein by venipuncture. Collected blood was transferred into the test tube and serum was separated from cells by centrifugation. Following Ferrokinetic profiles were determined on Roche/Hitachi Cobas C Systems.

Investigations include Serum ferritin, Total iron binding capacity (TIBC)

All investigations were performed at the beginning and the end of the study (after six months).

For this study we registered clinical data and other relevant details of cases by filling a proforma.

Data was analyzed on SPSS version 16.0. (IBM, Incorporation, USA). The continuous variables were be analyzed by student's t-test. The results are presented as mean \pm S.E.M (standard error of mean) and frequency (\%) respectively. The significant $\mathrm{p}$-value was taken at $\leq 0.05$.

This study was conducted strictly under the ethical rules after its approval from ethical committee of LUMHS Jamshoro. A written proforma was taken from each patient and risks and benefits were explained in detail to all included subjects. All the information regarding participants was kept confidential.

\section{RESULTS}

The mean \pm SEM (standard error of mean) age in the groups A(oral iron + rHuEPO) and Group B (I/V iron + rHuEPO) was noted as $41.65 \pm 1.35$, and $40.38 \pm 1.35$ years respectively ( $\mathrm{t}$-value $0.669, \mathrm{P}=0.50$ ).

Baseline mean \pm S.E.M of serum ferritin was noted as $21.16 \pm 1.76$ and $25.0 \pm 2.60 \mathrm{ng} / \mathrm{dl}$ in groups $A$ (oral iron + rHuEPO) and Group B respectively $(P=0.226)$. A significant increase in serum ferritin levels was noted in both Groups A and Group B at $6^{\text {th }}$ month compared to baseline $(P=0.0001)$. Rise in serum ferritin was more prominent in group $B(I / V$ iron + rHuEPO) subjects. The serum ferritin in Group B (I/V iron + rHuEPO) was raised to $139.43 \pm 1.77 \mathrm{ng} / \mathrm{dl}$ compared to Group A (oral iron + rHuEPO) $98.43 \pm 0.92 \mathrm{ng} / \mathrm{dl}$ ( $P=0.0001)$ (Table I \& Graph I).

Groups A (oral iron + rHuEPO) and Group B (I/V iron 
Sadat Memon, Nasreen Qazi, Shafiq ur Rehman Memon, Jamil Laghari

TABLE I: SERUM FERRITIN (NG/DL) OF STUDY SUBJECTS $(n=80)$

\begin{tabular}{|l|r|r|r|r|r|}
\hline & \multicolumn{2}{|c|}{ Group A } & \multicolumn{2}{c|}{ Group B } & \multicolumn{1}{c|}{ P-value } \\
\hline & Mean & \multicolumn{1}{|c|}{ SEM } & \multicolumn{1}{c|}{ Mean } & \multicolumn{1}{c|}{ SEM } & \\
\hline (Day 0) & 21.16 & 1.76 & 25.0 & 2.60 & $0.226 \uparrow$ \\
\hline $6^{\text {th }}$ month & 98.43 & 1.77 & 139.03 & 0.92 & 0.0001 \\
\hline$t$ - $P$ value Non-significant
\end{tabular}

TABLE II: TOTAL IRON BINDING CAPACITY (TIBC) ( $\mu \mathrm{G} / D L)$ OF STUDY SUBJECTS $(n=80)$

\begin{tabular}{|l|c|r|r|r|r|}
\hline & \multicolumn{2}{|c|}{ Group A } & \multicolumn{2}{c|}{ Group B } & \multicolumn{1}{c|}{ P-value } \\
\hline & Mean & SEM & Mean & SEM & \\
\hline Baseline (Day 0) & 450.20 & 0.49 & 449.62 & 0.87 & $0.53 \uparrow$ \\
\hline $6^{\text {th }}$ month & 309.23 & 9.32 & 245.05 & 4.19 & 0.0001 \\
\hline$t-P$ value Non-significant
\end{tabular}

+ rHuEPO) showed Baseline mean \pm SEM of TIBC as $450.2 \pm 0.49$ and $449.62 \pm 0.87 \mu \mathrm{g} / \mathrm{dl}$ respectively $(P=0.53)$, this is indicating severe iron deficiency in both groups. A significant decrease in TIBC level was noted in both Groups A (oral iron + rHuEPO) and Group B (I/V iron + rHuEPO) at $6^{\text {th }}$ month compared to baseline $(P=0.0001)$. Decrease in TIBC was statistically significantly found in the group $B$ subjects. At $6^{\text {th }}$ month, the TIBC in Group B (I/V iron + rHuEPO) was reduced to $245.05 \pm 4.19 \mu \mathrm{g} / \mathrm{dl}$ compared to Group A (oral) $309.23 \pm 9.32 \mathrm{ng} / \mathrm{dl}(\mathrm{P}=0.0001)$ (Table II \& Graph II).

\section{DISCUSSION}

Anemia in CRF patients is a common presentation that's the reason the present study was performed to evaluate the efficacy of intravenous and oral iron preparations in patients of CKD who are already receiving $\mathrm{rHuEPO}$. It was observed in present study that there was a significant increase in serum ferritin levels in both Groups $A$ and $B$ at $6^{\text {th }}$ months as compared to baseline $(P=0.0001)$ but rise in serum ferritin was more pronounced in the group $B$ at $6^{\text {th }}$ month, as serum ferritin raised to $139.43 \pm 1.77 \mathrm{ng} / \mathrm{dl}$ as compared to Group A (oral) $98.43 \pm 0.92 \mathrm{ng} / \mathrm{dl}$ which is highly significant $(P=0.0001)$ (Table I and Graph I). The finding of serum ferritin at $6^{\text {th }}$ month of present study is consistent with Tobli JE $2015^{17}$ as they reported $291.6 \pm 27.4 \mu \mathrm{g} / \mathrm{L}$.

A significant increase of serum ferritin levels of present study is also consistent with Bailie GR et $\mathrm{al}^{19}$ study.

Our results are also in accordance with MacDougall IC $2013^{18}$ who concluded that intravenous iron is an ideal modality of replenishing the serum iron and ferritin promptly and by far in both dialysis-dependent and non-dialysis chronic kidney disease (CKD) patients without compromising the safety.

At baseline mean total TIBC was very high; $450.2 \pm 0.49$ and $449.62 \pm 0.53 \mu \mathrm{g} / \mathrm{dl}$ in groups $A$ and $B$ respectively but there was a significant decrease in its levels in both Groups ( $A$ and $B$ ) at end of study as compared to baseline $(P=0.0001)$ (Table I and Graph I). Decrease in TIBC was more statistically significant in the Group B as compared to Group A. These findings are consistent with MacDougall IC $2013^{18}$, Pisani $A$ et $a^{20}$ and Quinbi WY et $\mathrm{al}^{21}$.

The findings of present study prove that the Intravenous iron dextran therapy when included as add-on therapy with recombinant human erythropoietin (rHuEPO) may help in reducing the incidence of anemia related morbidity and mortality in chronic kidney disease (CRF) patients.

\section{CONCLUSION}

The present study concludes that, the intravenous iron dextran therapy combined with recombinant human erythropoietin (rHuEPO) is more effective than oral iron therapy combined with recombinant human erythropoietin (rHuEPO) in improving the Serum ferritin and TIBC in patients with chronic renal failure.

\section{RECOMMENDATIONS}

1. Future controlled studies of intravenous iron therapy in patients with chronic kidney disease are warranted to confirm the observed beneficial effects.

2. Intravenous iron therapy should be considered for 
the evaluation and amelioration of potential anemia related morbidities such as the fatigue, quality of life and exercise capacity in chronic kidney disease patients.

Conflict of interest: There was no conflict of interest.

Funding: There was no any funding agency.

\section{REFERENCES}

1. Jelkmann W. Regulation of erythropoietin production. J Physiol. 2011; 589(Pt 6):1251-8. doi: 10.1113/jphysiol.2010.195057

2. Johansen KL, Finkelstein FO, Revicki DA, Gitlin M, Evans C, Mayne TJ. Systematic review and meta-analysis of exercise tolerance and physical functioning in dialysis patients treated with erythropoiesis-stimulating agents. Am J Kidney Dis. 2010; 55(3):535-48. doi: 10.1053/ j.ajkd.2009.12.018.

3. Patel TV, Singh AK. Anemia in chronic kidney disease: new advances. Heart Fail Clin. 2010; 6 (3):347-57. doi: 10.1016/j.hfc.2010.02.001.

4. Fernandez-Rodriguez AM, Guindeo-Casasus MC, Molero-Labarta T, Dominguez-Cabrera C, Hortal Casc $n$ L, Perez-Borges $P$, et al. Diagnosis of iron deficiency in chronic renal failure. Am J Kidney Dis. 1999; 34(3): 508-513.

5. Suzuki M, Hada Y, Akaishi M, Hiroe M, Aonuma $\mathrm{K}$, Tsubakihara $\mathrm{Y}$, et al. Effect of anemia correction by erythropoiesis-stimulating agents on cardiovascular function in non-dialysis patients with chronic kidney disease. Int Heart J. 2012; 53 (4):238-43.

6. Rambod M, Kovesdy CP, Kalantar-Zadeh K. Combined high serum ferritin and low iron saturation in hemodialysis patients: the role of inflammation. Clin J Am Soc Nephrol. 2008; 3(6): 1691-1701. Doi: 10.2215/CJN.01070308

7. Fishbane S, Maesaka JK. Iron Management in End-Stage Renal Disease. Am J Kidney Dis 1997; 29(3):319-33.

8. Besarab B. Anemia and iron management. Semin Dial. 2011; 24:498-503.

9. Ji P. Pericytes: new EPO-producing cells in the brain. Blood. 2016; 128(21):2483-5. doi: 10.1182/blood-2016-10-743880

10. Miskowiak KW, Vinberg M, Christensen EM, Bukh JD, Harmer CJ, Ehrenreich $\mathrm{H}$, et al. Recombinant Human Erythropoietin for Treating Treatment-Resistant Depression: A Double-Blind, Randomized, Placebo-Controlled Phase 2 Trial. Neuropsychopharmacology. 2014; 39(6):1399-
1408. Doi: 10.1038/npp.2013.335

11. Can C, Emre S, Bilge I, Yilmaz A, Sirin A. Comparison of recombinant human erythropoietin and darbepoetin alpha in children. Pediatrics Int. 2013; 55(3):296-9. Doi: 10.1111/ped.12085.

12. Kapitsinou PP, Liu Q, Unger TL, Rha J, Davidoff $\mathrm{O}$, Keith B, et al. Hepatic HIF-2 regulates erythropoietin responses to hypoxia in renal anemia. Blood 2010; 116(16):3039-48. doi: 10.1182/blood-2010-02-270322.

13. Stancu S, Barsan L, Stanciu A, Mircescu G. Can the response to iron therapy be predicted in anemic nondialysis patients with chronic kidney disease? Clin J Am Soc Nephrol. 2010; 5(3):409416. doi: 10.2215/CJN.04280609

14. Van Wyck DB, Roppolo M, Martinez CO, Mazey RM, McMurray S, United States Iron Sucrose (Venofer) Trials Group. A randomized, controlled trial comparing IV iron sucrose to oral iron in anemic patients with nondialysis-dependent CKD. Kidney Int. 2005; 68(6):2846-56.

15. Agarwal R, Rizkala AR, Bastani B, Kaskas MO, Leehay DJ, Besarab A. A randomized controlled trial of oral versus intravenous iron in chronic kidney disease. Am J Nephrol. 2006;26(5):445-54.

16. Macdougall LC, Bock AH, Carrera F, Eckardt KU, Gaillard C, Van Wyck D, et al. FIND-CKD: A randomized trial of intravenous ferriccarboxymaltose versus oral iron in patients with chronic kidney disease and iron deficiency anaemia. Nephrol Dial Transplant. 2014; 29(11):2075-2084. doi: 10.1093/ndt/gfu201

17. Toblli JE, Di Gennaro F. Switching Patients with Non-Dialysis Chronic Kidney Disease from Oral Iron to Intravenous Ferric Carboxymaltose: Effects on Erythropoiesis-Stimulating Agent Requirements, Costs, Hemoglobin and Iron Status. PLoS One. 2015; 10(4): e0125528. doi: 10.1371/journal.pone.0125528.

18. MacDougall IC, Geisser P. Use of Intravenous Iron Supplementation in Chronic Kidney Disease: An Update. Iran J Kidney Dis. 2013; 7(1):9-22.

19. Bailie GR, Larkina M, Goodkin DA, Li Y, Pisoni $\mathrm{RL}$, Bieber $\mathrm{B}$, et al. Data from the Dialysis Outcomes and Practice Patterns Study validate an association between high intravenous iron doses and mortality. Kidney Int. 2015; 87(1):16268.

20. Pisani A, Riccio E, Sabbatini M, Andreucci M, Del Rio A, Visciano B. Effect of oral liposomal iron versus intravenous iron for treatment of iron deficiency anaemia in CKD patients: a 
randomized trial. Nephrol Dial Transplant. 2015; 30(4):645-52.

21. Qunibi WY, Martinez C, Smith M, Benjamin J, Mangione A, Roger SD. A randomized controlled trial comparing intravenous ferric carboxymaltose with oral iron for treatment of iron deficiency anaemia of non-dialysis-dependent chronic kidney disease patients. Nephrol Dial Transplant 2011; 26(5):1599-1607. doi: 10.1093/ndt/gfq613.

\section{垱}

AUTHOR AFFILIATION:

Dr. Sadat Memon (Corresponding Author)

Lecturer/Demonstrator

Department of Pharmacology and Therapeutics

Liaquat University of Medical \& Health Sciences

(LUMHS), Jamshoro, Sindh-Pakistan.

E.mail : sadatmemon1@gmail.com

\section{Dr. Nasreen Qazi}

Professor, Department of Pharmacology and Therapeutics LUMHS, Jamshoro, Sindh-Pakistan.

\section{Dr. Shafiq ur Rehman Memon}

Ex Professor Department of Urology

LUMHS, Jamshoro, Sindh-Pakistan.

\section{Dr. Jamil Laghari}

Associate Professor

Department of Pharmacology and Therapeutics

LUMHS, Jamshoro, Sindh-Pakistan. 